this is to be done otherwise than by wars, pestilences, and famines, it will demand a powerful international authority. This authority should deal out the world's food to the various nations in proportion to their population at the time of the establishment of the authority. If any nation subsequently increased its population it should not on that account receive any more food. The motive for not increasing population would therefore be very compelling. What method of preventing an increase might be preferred should be left to each state to decide.

But although this is the logical solution of the problem, it is obviously at present totally impracticable. It is quite hard enough to create a strong international authority, and it will become impossible if it is to have such unpopular duties. There are, in fact, two opposite difficulties. If at the present moment the world's food were rationed evenly the Western nations would suffer what to them would seem starvation. But, on the other hand, the poorer nations are those whose population increases fastest, and who would suffer most from an allocation which was to remain constant. Therefore, as things stand, all the world would oppose the logical solution.

Taking a long view, however, it is by no means impossible that the population problem will in time solve itself. Prosperous industrial countries have low birth rates; Western nations barely maintain their numbers. If the East were to become as prosperous and as industrial as the West, the increase of population might become sufficiently slow to present no insoluble problem. At present Russia, China, and India are the three great reservoirs of procreation and poverty. If those countries reached the level of diffused well-being now existing in America their surplus population might cease to be a menace to the world.

In general terms, we may say that so far as the population problem is concerned a scientific society could be stable if all the world were as prosperous as America is now. The difficulty, however, is to reach this economic paradise without a previous success in limiting population. It cannot be done as things are now without an appalling upheaval. Only government propaganda on a large scale could quickly change the biological habits of Asia. But Eastern governments would never consent to this except after defeat in war. And without such a change of biological habits Asia cannot become prosperous except by defeating the Western nations, exterminating a large part of their population, and opening the territories now occupied by them to Asiatic immigration. For the Western nations this is not an attractive prospect, but it is not impossible that it may happen. Irrational passions and convictions are so deeply involved in the problem that only an infinitesimal minority, even among highly educated people, are willing even to attempt to consider it rationally. That is the main reason for a gloomy prognosis.

Coming, finally, to the psychological conditions of stability, we find again that a high level of economic prosperity is essential. This would make it possible to give long holidays with full pay. In the days before currency restrictions dons and public schoolmasters used to make their lives endurable by risking death in the Alps. Given secure peace, a not excessive population, and a scientific technique of production, there is no reason why such pleasures should not be open to everybody. There will be need also of devolution, of a great extension of federal forms of government, and of keeping alive the kind of semiindependence that now exists in English universities. But I will not develop this theme, as I have dealt with it in my Reith lectures on "Authority and the Individual."
My conclusion is that a scientific society can be stable given certain conditions. The first of these is a single government of the whole world, possessing a monopoly of armed force and therefore able to enforce peace. The second condition is a general diffusion of prosperity, so that there is no occasion for envy of one part of the world by another. The third condition (which supposes the second fulfilled) is a low birth rate everywhere, so that the population of the world becomes stationary, or nearly so. The fourth condition is the provision for individual initiative both in work and play, and the greatest diffusion of power compatible with maintaining the necessary political and economic framework.

The world is a long way from realizing these conditions, and therefore we must expect vast upheavals and appalling suffering before stability is attained. But, while upheavals and suffering have hitherto been the lot of man, we can now see, however dimly and uncertainly, a possible future culmination in which poverty and war will have been overcome, and fear, where it survives, will have become pathological. The road, I fear, is long, but that is no reason for losing sight of the ultimate hope.

\section{VISCERAL ACTINOMYCOSIS*}$$
\text { BY }
$$

\section{ZACHARY COPE, B.A., M.D., M.S., F.R.C.S. \\ Consulting Surgeon, St. Mary's Hospital, and Bolingbroke Hospital}

The subject I have chosen has never previously been discussed in any lecture in the series, yet for a reason which I shall give I think it would have been of special interest to Dr. Bradshaw. Dr. William Wood Bradshaw became a Fellow of this College in 1854. For many years he was in practice at Andover and Reading, and he was at one time vice-president of the Reading Pathological Society. He died in 1866, and his widow, Mrs. Sally Bradshaw, by a will dated September 6,1875 , left money to found a lectureship whereby the memory of her husband might be perpetually honoured. This will was proved on August 26, 1880.

Between these two dates something interesting had happened : actinomyces had been discovered and the disease "actinomycosis" named. The discovery was made by Bollinger in 1876, and the name was coined by his friend Harz. Now Dr. Bradshaw did not publish many clinical articles, but if you turn to the Lancet for 1846 you will find that he gave a remarkable account of a case of abdominal abscess. The description was of a slowly developing hard mass in the right iliac fossa culminating after two years in an abscess, which discharged pus. The patient improved under treatment by potassium iodide, but his condition relapsed and the right thigh became permanently flexed. The patient's general state deteriorated and there was a fatal issue. From the account given there can be little doubt that this was a case of actinomycosis, which, at the time when Dr. Bradshaw's article was published, was unknown. The first case to be noted in man was by Ponfick in 1879, so that by the time Mrs. Bradshaw's will had been proved actinomycosis had been added

*The Bradshaw Lecture delivered at the Royal College of Surgeons of England on November 10 . This lecture is being published, with of England on November in the Royal College of Surgeons of England. It is published here by kind permission of the President of the College. 
to the list of diseases affecting human beings. An excellent clinical account of the disease was published by Israël in 1886.

For many years our knowledge of the actinomyces which causes disease in man and animals remained insecure, but a series of careful observers-Wolff (1891), Homer Wright (1905), Naeslund (1931), Colebrook (1920), and othersestablished certain facts which even now are not sufficiently known. Actinomycetes are very common, and are frequently found in the soil. Most of them are aerobic organisms which seldom cause pathological lesions in man. Occasionally the Actinomyces asteroides may affect the lungs. The only actinomyces which commonly gives rise to disease in man is the Actinomyces bovis or Actinomyces israeli, which will grow only when oxygen is excluded or present in minimal amount. This common pathological agent, which is responsible for nearly all the lesions in man, has never been found outside an animal body. It has never been found on grasses or grains, on hay or on straw, and the farmhand is not more likely to become infected than the city clerk. In man it often lies latent in the carious crevices of teeth or in the deep crypts of the tonsil. It is relatively as common in the peer as in the peasant, but, strangely enough, is more common in men than in women.

That the organism which is so frequently present in the body does not more often cause disease is due to the fact that it finds difficulty in penetrating normal epithelial surfaces; when by accident, by disease, or by necessary operation the epithelial surface is broken the actinomyces may escape into the cellular tissues and begin to grow, well away from the surface. The extraction of a tooth or the perforation of the appendix will be sufficient to allow its escape. Exceptionally, the tissue reaction is acute and may form an abscess in which the fungus is found plentifully but not in granules. More commonly the reaction leads to the formation of a mass of hard fibrous tissue, almost avascular, and on section looking very much like a sarcoma or a scirrhous carcinoma; embedded in this may sometimes be seen small abscesses, but in many cases it needs very careful microscopical examination to find any trace of the organism. Sooner or later softening occurs and an abscess is formed. The inflammation spreads by continuity and often follows the line of least resistance ; it has little respect for any tissue, always excepting surface epithelium and dense fascia such as the dura mater.

\section{Some Problems}

The dense fibrous reaction of the undifferentiated mesenchyme cells, its chronicity, and its avascularity give rise to some problems and furnish material for reflection. How is it that such minute portions of the actinomyces can form such a mass of tissue, which is sometimes almost like cartilage? There must be some powerful irritant or stimulator. Whence does it come? Twenty-five years ago Carrel taught us that fibroblasts were maintained in a true state of cultivation only by embryonic tissue juice or extracts of some adult tissues or of leucocytes. But the only element which is peculiar to the actinomycotic reaction is the actinomyces, and it is difficult to escape the conclusion that the stimulator of the mesenchyme cells comes from some degenerative or secretory product of the organism itself. We now know that several of the fungi can produce substances of immense power-witness actinomycin, streptomycin, and penicillin-and it seems reasonable to assume that the extraordinary stimulus of fibrous-tissue formation comes from the actinomyces. There is an interesting sidelight on this view. Clinically, we know that treatment by $x$ rays may cause a softening of this hard fibrous tissue, and when we recall the statement of Carrel that the substances which he found promoted the growth of fibroblasts were sensitive to $x$ rays and to radium we may be right in concluding that the softening process may be the consequence of the destruction of the stimulating substance.

Another problem : How is it that the actinomyces can remain latent in the tissues for months or years? In the first place, being microaerophilic, it can maintain its existence in avascular tissue. Then there is little doubt that the arrangement of the small foci of the fungus in the tissues-growing hyphae surrounded by a palisade of clubs-is beneficial. Thirdly, the conglomeration of the fungus into granules gives added protection. Some recent very interesting work of Per Holm (1948) supports this view. He found that suspensions of pathological actinomyces were as sensitive to penicillin as staphylococci, but it required much more penicillin to destroy the organism when it was collected into the colony usually known as the "sulphur granule." There was one type of 'fungus which formed less firm and more diffluent granules, which were found to be very sensitive to penicillin. Roberts, Tubbs, and Bates in 1945 published an account of a case which was extremely sensitive to penicillin, and in that case they noted that the granules were very viscous and weblike rather than in a compact mass. So the firm "sulphur granule" seems to have a protective function on the contained fungus.

\section{Source of Actinomycotic Infection}

Whence comes the actinomycotic infection? We must put aside the traditional and popular fairy-tale about infection from grass or straw, while admitting that many textbooks are still doing their best for the older and fallacious teaching. Are we to consider it likely that infection comes from contact with the cow or from infected milk? There is very little, in fact negligible, evidence of this. The disease is so rare in animals other than the cow that we need not consider this source. We have only one possibility left -infection from one human being to another.

Apart from one striking case in which infection probably took place by the contact of kissing, there is no evidence for direct contagion. We are forced to the conclusion that infection with actinomycosis takes place by indirect means. Professor Wilkinson has told me of one case in which infection came from another patient in the same ward who happened to be the victim of the disease ; but, ordinarily, infection may come not from a diseased person but from a carrier. The organism often exists in the crevices of carious teeth, and it needs little imagination to see how many opportunities there are for the organism to pass from one person to another. The carious tooth is the usual place from which the trouble springs. Let us now follow the actinomyces in its journey to one or other part of the body from its favourite haunt in the mouth.

As one would expect, more than a half of all the cases occur in the immediate vicinity of the jaw-in the jaw itself, the cheek, the submaxillary and submental regions, and the neck. To emphasize the connexion between infection and the carious tooth I would mention the case of a young woman whom I treated 30 years ago for a large cyst of the lower jaw which gave eggshell crackling; the fang of a carious tooth was in the roof of the cyst, which was filled completely by actinomycotic pus.

When once the fungus has obtained lodgment in the mouth it is inevitable that from time to time portions will 
be swallowed and pass through the alimentary canal. In most cases no harm results, but in areas where it may meet an ulcerated surface, or when inflammatory processes give it an opportunity to extend, it may cause serious trouble. It may form a granuloma in the wall of the stomach, and several cases have been recorded in which partial gastrectomy has been performed under the impression that the condition was a cancer. A number of cases of infection of the peritoneum or of adjacent viscera have followed the perforation of a gastric or duodenal ulcer. One case has been recorded in which on microscopical examination the organism was seen at the site of a perforation. When once it has reached the peritoneal cavity it may cause a subphrenic abscess or may even gravitate to the pelvis and form a tumour there. The intestinal contents pass quickly along the small bowel, and it is very rare for the actinomyces to cause any lesion there, though a remarkable instance has been recorded by Sir Gordon Gordon-Taylor (1930).

The vermiform appendix, however, provides a comfortable home and at the same time offers a chance of its escape, so that perforative appendicitis is by far the commonest precursor to abdominal actinomycosis. In a number of recorded cases the perforation of the appendix has communizated direct with sinuses in the inflammatory mass. When once the process has started, the lesion may extend by contiguity downward into the pelvis, backward into the psoas muscle, upwards towards the kidney, and medialwards to the vertebral column. Even the liver may be directly attacked. The best demonstration of this remarkable method of spread is seen in the case which was under the care of Sir Heneage Ogilvie (1940); in this case, when a sinus in the right iliac region was injected with an opaque solution and was radiographed there resulted a picture showing that the sinus communicated direct with tracks which ramified in the liver, traversed the diaphragm, and were directly connected with the bronchioles in the right lung.

The colon and rectum are not so commonly affected, but quite often enough to make it necessary always to consider this disease as a possibility in discussing the diagnosis; in nearly every case there develops an abdominal or pelvic tumour which usually simulates a malignant growth, and in several cases has been excised with that pre-operative diagnosis.

Thoracic infections are also due to spread from the mouth. This may result in several ways. A rare accident, but one which befell a former distinguished member of the Court of Examiners of this College, is the accidental falling of an extracted carious tooth into one of the bronchi ; in the case referred to, an actinomycotic abscess formed in the lung round the tooth, and this needed open drainage for its cure. More often minute portions of the fungus are aspirated into the bronchial tree, where they may persist sometimes in a bronchiectatic cavity or in some small inflammatory focus. This view has received remarkable confirmation lately. Two years ago E. B. Kay published some rather illuminating facts giving the results of his investigation of 240 consecutive patients treated for broncho-pulmonary infections. He bronchoscoped them all and took cultures of the sputum and of the bronchial secretions. In 65 of these cases, which included examples of pneumonitis, lung abscess, bronchiectasis, aspiration pneumonia, suppuration distal to a bronchial carcinoma, and simple bronchitis, he was able to isolate and to culture the Act. israeli.

The wonder is that pulmonary actinomycosis is comparatively rare, for the microbe is so often there merely awaiting the chance to invade the tissues. In any case, we have a simple explanation of the disease which starts in the lung tissue. But when it starts in the mediastinum, as it often does, we must seek another route of infection, and most likely this is by the escape of the organism through the oesophageal wall. We cannot watch this process, and, as in the cheek, the organism leaves little or no trace of the route by which it escaped, but clinically this method of infection fits in best with the facts; frequently an empyema is the next stage, and then the lung may became involved. It is the rule for pulmonary actinomycosis to invade the thoracic wall and come to the surface. The thorax sometimes becomes infected by the bursting of a hepatic abscess through the diaphragm, or it may become involved by a low cervical infection descending into the superior mediastinum.

The cranial cavity may be affected by infection spreading up from the face through the basal foramina, or the brain may be infected via the blood stream. There is in addition a very remarkable single lesion which has occasionally formed in the region of the septum lucidum or third ventricle ; this consists of a filbert-sized actinomycoma which ozcurs without any other trace of similar infection discoverable in the body. Until recently only six of these extraordinary solitary lesions had been described, but four years ago a seventh-a pedunculated tumour in the third ventricle-was recorded by T. G. Orr. I have previously stated, and still think, that in these rare cases infection travels up from the upper meatus of the nose via the sheath of the olfactory nerves.

The vertebral co'umn may be involved in either abdominal or thoracic actinomycosis, but the spinal cord itself is rarely infected. The vertebral column is characteristically affected in a way quite different from that in any other form of infection. The process commonly affects the bodies and transverse processes, but it may invade any part with which it comes in contact. There is a very slow process of absorption but a simultaneous formation of new bone which maintains the framework and strength of the bodies, so that collapse of a vertebra is rarely seen and is never so comp'ete as in tuberculosis. The intervertebral disks are involved late and often hardly at all. The disease may surround the exits of the nerves and may cause severe pain, but it is rare for the fungus to penetrate the spinal dura. The $x$-ray picture of vertebral actinomycosis is often pathognomonic, for the side view of the bodies gives one the impression of a coarse sieve, each opening being surrounded by a circle of denser bone.

\section{Symptoms}

How is it possible to enumerate, still less describe, the symptoms caused by visceral actinomycosis? It would require a short textbook to do so. In the early stages in any part there is nothing at all characteristic. The onset may be acute, subacute, or insidiously chronic. Irregular fever is the rule and there is moderate leucocytosis. Whenever the condition has existed for some time there will be increasing anaemia, lowered serum protein, wasting, and loss of strength. Pain may be absent or very severe, particularly if the vertebral column be attacked.

The local symptoms vary greatly according to the part affected. In the abdomen there is usually the formation of a hard swelling, which is significant when it forms around the sinus left by the drainage of an appendicular abscess. When such a tumour develops in the pelvis or around the colon without any previous warning it is usually taken for a malignant growth, although it seldom causes 
acute obstruction. In the liver, which it may reach via branches of the portal vein or by direct contact, it may take the form of one or more localized tumour-like masses, or it may invade a large portion of one of the lobes and lead to the formation of large abscesses which disintegrate the glandular substance. I have known at least two cases in which fairly small localized masses in the liver were impossible of diagnosis until a portion had been removed for biopsy. Hepatic actinomycosis may lead to subphrenic abscess and pleural effusion.

When actinomycosis attacks the contents of the thorax it may closely simulate tuberculosis, pneumonitis, pleural effusion, empyema, or malignant growth ; when it invades the mediastinum it may look like a mass of glands, or, when the vertebrae are involved, simulate osteomyelitis or give rise to meningeal symptoms.

Wherever it may penetrate, the actinomycotic process sooner or later always softens in one part or another and forms an abscess which generally comes to the surface of the body, often some way from the main focus. Such an abscess differs from that due to tuberculosis in that it is generally painful, causes redness and oedema of the skin and adjacent parts, and contains a thicker pus from which the granules can usually be obtained.

You will now understand why there are no characteristic symptoms. Visceral actinomycosis has a definitely. ugly face but wears many masks : so many clinical pictures but the same insidious disease. One must therefore always consider the possibility of this disease.

\section{Diagnosis}

Even when one does consider its possibility there remains the difficulty of differential diagnosis. Actinomycosis might well be called the " most misdiagnosed disease." I know of no disease which is so often missed by experienced clinicians. Too many cases are diagnosed for the first time at necropsy. It is the rule-for visceral actinomycosis to pursue its course for many months, sometimes for a year or two, before the possibility of its presence occurs to the observer. There are several reasons for this. First, we have no reliable reaction or blood test for the disease. Agglutination, complement fixation, estimation of the opsonic index, a precipitin test, and a cutaneous reaction have all been tried and advocated, but Naeslund (1931) found none of them reliable. Secondly, in the case of deep visceral lesions it may be months before an abscess from which the organism may be obtained comes to the surface. Moreover, it requires care and time to culture actinomyces, which soon dies if the pus dries, and which takes a much longer time to grow than the usual septic organisms. I purposely repeat that a final and important cause is that the disease may not be on the list of possible diagnoses which the observer goes through as a routine. The incidence of diseases has so altered through the last 40 years that (in my experience at least) it is now more common to meet with actinomycosis than with a syphilitic gumma. They should both be considered in doubtful cases.

The differential diagnosis has to be made from other causes of acute and chronic inflammation and from malignant growth. Syphilis may be excluded by the Wassermann reaction or other specific test. Tuberculosis and malignant disease of the lung cannot always be differentiated until an abseess has formed. The lesions in the intestine may closely simulate cancer, for there are many clinical resemblances. Both are often insidious in origin and prolonged in development, both advance inexorably into the neighbouring tissues, and in neither case is much respect paid to the nature of those tissues except in the case of lymphatic glands. In each case hard tumours may be formed. Finally, even microscopical examination may not reveal the fungus unless many sections are examined and the fibrous tissue reaction has led to the diagnosis of fibrosarcoma.

Since certain diagnosis can be made only by finding the actinomyces in the pus or tissues it is clear that there should be the closest co-operation between the pathologist and the clinizian in diagnosing this disease. The surgeon's duty is not finished when he opens the abscess; he fails in his duty if he does not call the pathologist into consultation.

\section{Treatment}

During the past ten years the treatment of actinomycosis has changed remarkably for the better, and visceral infection, which gave a mortality of more than $50 \%$, has now had to submit to a degree of control or even cure which was previously impossible. Much of the treatment used in 1939 is now out of date, although the books 'still insert them. Copper sulphate, formalin, salvarsan, thymol-all formerly advocated by some-have been superseded by the sulpha drugs and the antibiotics. There is little need for vaccines, and $x$ rays are not so often required therapeutically, though they are sometimes of value in diagnosis. With the possibility of cure has come the fuller realization that visceral actinomycosis has a serious effect upon the general health and that constitutional treatment is very important. Amyloid is recognized as a serious complication.

Constitutional treatment consists in giving a plentiful and nourishing diet and carrying out the same rules with regard to fresh air and sunshine as in tuberculosis. Extra milk should be provided and the anaemia treated by haematinics or, if necessary, by transfusion. In no case should any operative measures be undertaken before the general strength has been built up.

With regard to drug treatment, iodine and its derivatives are still of value in promoting absorption, but potassium iodide is not a specific and need never be given in large doses. The best method of administering iodine is that of Chitty (1929), who recommends $5 \mathrm{~min}$. $(0.3 \mathrm{ml}$.) of tinctura iodi in a glass of milk thrice daily.

The discovery in 1935 by Domagk that prontosil red could cure streptococcal infection in mice led to its use in streptococcal and other infections in man. In 1937 Poulton, of Guy's, tried it in a case of streptococcal infection complicating a case of actinomycosis, and the patient improved greatly; the improvement, however, was attributed to the effect of the drug on the streptococcal infection. The following year a young officer in the R.A.M.C., by name Oliver Walker, was faced at Millbank by the case of a soldier suffering from actinomycosis following perforative appendici:is ; there was a hard lump surrounding a right iliac sinus, and no benefit had accrued under treatment by potassium iodide and thymol. In this case Walker tried the effect of $1 \mathrm{~g}$. of sulphanilamide three times a day for two periods of five days, and he was gratified to find that the whole condition rapidly resolved. He reported his success in a short and inconspicuous note (Walker, 1938).

This report encouraged two doctors at Cook County Hospital, Chicago (Miller and Fell, 1939), to report a similar case which they had independently treated successfully by the same drug. Soon many other cases were reported by Hall (1939), Ogilvie (1940), and Dorling and Eckhoff (1940), so that it became established that several of the 
sulpha group of drugs had a definite beneficial effect on actinomycosis. In 1941 Cutting and Gebhardt showed that sulphanilamide, sulphathiazole, and sulphadiazine had a definite inhibiting effect on the actinomyces in vitro.

\section{Penicillin}

But very soon after this a still more powerful therapeutic substance was introduced into surgery-a substance discovered by a Fellow of this College. Forty years ago this last June, as I was waiting with trepidation for the result of the Fellowship of this College, I was pleased to see go in front of me into the Library to receive his Fellowship a young doctor called Alexander Fleming, who, needless to say, had passed at his first attempt. After gaining his Fellowship Fleming retired to work in the pathological laboratory, and one feared that he might be lost to surgery. But he retired only to do greater things for surgery after twenty years, for no single discovery in this generation has so improved the possibilities of surgery as the discovery of penicillin (Fleming, 1929).

When during the war Florey and Chain purified this substance and showed more clearly its clinical possibilities it was not long before its effect on the actinomyces was demonstrated. One of the first series of clinical trials by Florey (Florey and Florey, 1943) was a case of empyema in which a streptothrix was found; treatment by penicillin in comparatively small doses caused the disappearance of the streptothrix from the discharge. Since that time penicillin has been used more extensively for the treatment of actinomycosis, and as the supply became more plentiful greater doses were given and better results obtained. In 1947 Nichols and Herrell reviewed 98 cases of the disease, of which 45 were treated by penicillin and 53 without it. The period of disability caused by the disease was shortened by penicillin and was most striking with visceral actinomycosis. This is shown in the figures they quote :

Pulmonary.-With penicillin: five retarded, four failures. Without penicillin: 13, of which only one improved.

Abdominal.-With penicillin: seven, of which five were cured. Without penicillin: 14, of which nine died, four were still ill, and one recovered.

Pelvic.-With penicillin: three, all cured. Without penicillin: one, not cured.

In reading through the case reports from year to year certain facts stand out clearly. At first short courses of comparatively small doses were given; improvement occurred but did not prove lasting, so that repeated courses of treatment were required. Later, when bigger doses were used, the results were much better and cure was sometimes attained. Often, however, recurrence took place after an interval of some months. It then became evident that for severe cases of visceral actinomycosis it was necessary to give large doses of penicillin for long periods of time without intermission. That at least has been my personal experience.

That it has not been my experience alone may be judged by the writings of others. In 1946 Decker laid it down that " penicillin should be given in large doses, 100,000 to 200,000 units per day for 10 to 14 days. After several weeks' rest repeated courses of the treatment over 12 months, or at any time of recurrence." Two years later other observers (Nichols and Herrell, 1948) found that the dose given to their patients varied from 800,000 to one million units daily and was continued for from two to seven weeks; they concluded that the dosage should be at least half a million un ts daily and should be continued for at least six weeks. It is true that many cases get well with less than these amounts, particularly abdominal cases, but in difficult thoracic lesions it will be found that these doses are on the low side and at least a million units daily will be needed.

Short courses of treatment with penicillin are unsatisfactory, for then recurrence is the rule. There should be no intermission until the patient has been free from symptoms for some weeks or months. This has been well recognized by Adamson and Hagerman (1948), who reported a case of pulmonary actinomycosis successfully treated by penicillin and sulphadital : "Thus when dealing with pulmonary actinomycosis the most appropriate procedure seems to be chemotherapeutic treatment continued until long after the clinical symptoms have subsided." This is no place to discuss the methods of administering the penicillin, but my own preference is for giving two large and concentrated doses by intramuscular injection twice in the 24 hours. Three-hourly injections may be a great trial to the patient, and the intravenous method is not so convenient and does not give better results.

When the response to penicillin is slow or absent there may be some advantage in combining it with one of the sulpha group of drugs. Many observers have claimed better results by the combination of the two drugs. Certainly one of the few recorded cures of actinomycosis of the liver was from treatment by the combination of penicillin with sulphamerazine (Bonney, 1947). In some of the recorded cures by the combined method the doses of penicillin were much smaller than would be considered necessary nowadays.

For those patients who do not respond to treatment by penicillin other antibiotics are available. Two years ago Costigan found streptomycin of benefit in a case of cervicofacial actinomycosis, and last year Keefer and Hewitt found it had a beneficial effect in a case of abdominal infection. This year Torrens and Wood, and Pemberton and Hunter, also proved the value of streptomycin in abdominal actinomycosis. The former gave $2 \mathrm{~g}$. a day for a month and then reduced the dose to $1 \mathrm{~g}$. daily for a further period; the latter gave $1 \mathrm{~g}$. daily for a month and let the patient take the drug by mouth. Usually the drug is given parenterally, for it is only slightly absorbed from the intestine. It cannot be continued for such long periods as penicillin without risk of toxic symptoms. Penicillin and streptomycin should not be given together, for the latter has a deleterious effect on the action of penicillin. There is another antibiotic-bacitracin (Meleney)-which has also been proved to have some curative power in actinomycosis, but this drug is not yet available in this country.

\section{Conclusion}

Here, then, we have several powerful drugs which can be used with great benefit against actinomycosis. We must now ask what place surgery has in treatment. The answer is-a diminishing one. Abscesses must be opened or, if small, aspirated. When the surgeon meets with a massive lesion of the stomach, intestine, or the kidney, excision of the affected part may be necessary; but it is never now needful to excise portions of lung or even to remove those masses of fibrous tissue which develop in this disease. In future, visceral actinomycosis will be treated chiefly by the antibiotics, the sulphonamide group of drugs, iodine in some form, and perhaps $x$ rays to soften the hard tissue, while constitutional treatment will require full attention.

We have advanced far in the last ten years, but there remain many doubtful points in the pathology of actinomycosis to be solved. It was due to a distinguished Fellow of this College that treatment leaped forward; I have the 
hope and faith to believe that some other Fellow. of the College, perhaps some young doctor in this Hall, may be stimulated by what I have said to attempt to solve the problems which still remain.

\section{REFERENCES}

Adamson, C. A., and Hagerman, G. (1948). Acta med. scand. 131, 23.

Bollinger, O. (1877). Zbl. med. Wiss., 15, 481.

Bonney, G. W. L. (1947). Brit. J. Surg., 34, 316.

Bradshaw, W. W. (1846). Lancet, 2, 529 .

Carrel, A. (1924). J. Amer. med. Ass., $82,255$.

Chitty, H. (1929). British Medical Journal, 1, 347.

Colebrook, L. (1920). Brit. J. exp. Path., 1, 197.

Costigan, P. G. (1947). Canad. med. Ass. J., 56, 431.

Cutting, W. C., and Gebhardt, L. P. (1941). Science, 94, 568

Decker, H. R. (1946). J. thorac. Surg., 15, 430.

Domagk, G. (1936). Klin. Wschr., 15, 1585.

Dorling, G. C., and Eckhoff, N. L. (1940). Lancet, 2, 707.

Fleming, A. (1929). Brit. J. exp. Path., 10, 226.

Florey, M. E., and Florey, H. W. (1943). Lancet, 1, 387.

Gordon-Taylor, Gordon (1930). The Dramatic in Surgery. Wright, Bristol.

Hall, W. E. B. (1939). J. Amer. med. Ass., 112, 2190.

Holm, Per (1948). Acta path. microbiol., scand.. 25, 376.

Israël, J. (1886). In Recent Essays on Bacteria, p. 643. New Sydenham Society, London.

Kay, E. B. (1947). Ann. intern Med., 26, 581.

Keefer, C. S., and Hewitt, W. L. (1948). The Therapeutic Value of Streptomycin, p. 255. Michigan.

Miller, E. M., and Fell, E. H. (1939). J. Amer. med. Ass., 112, 731

Naeslund. C.' (1931). Acta path. microbiol., scand., Suppl. 6.

Nichols, D. R., and Herrell, W. E. (1947). J. Lab. clin. Med., 32 1405 .

(1948). Ibid., 33, 521.

Ogilvie, W. H. (1940). British Medical Journal 2. 254

Orr, T. G. (1945). J. Amer. med. Ass. 127, 757.

Pemberton, H. S.. and Hunter. W. R. (1949). Lancet, 1, 1094.

Poulton, E. P. (1937). Proc. R. Soc. Med.. 31. 164.

Roberts, J. E. H., Tubbs, O. S., and Bates. M. (1945). Lancet, 1, 39

Torrens, J. A.. and Wood, M. W. W. (1949). Ibid., 1, 1091

Walker. O. (1938). Ibid., 1. 1219.

Wolff, M., and Israël. J.'(1891). Virchows Arch.. 126, 11

Wright, J. Homer (1905). J. Med. Res., 13, 349.

\section{VAGOTOMY FOR PEPTIC ULCER* INDICATIONS AND RESULTS}

BY

I. M. ORR, O.B.E., Ch.M., F.R.C.S.Ed.

Surgeon, Royal Infirmary, Preston; lately Lecturer in Surgery, Postgraduate Medical School of London

AND

\section{H. DAINTREE JOHNSON, F.R.C.S.}

Assistant Surgeon, Royal Free Hospital; Lecturer in Surgery, Postgraduate Medical School of London

It is now over two years since we reported from the Postgraduate Medical School a series of 50 peptic ulcer cases treated by vagus resection and concluded that results were promising enough to secure the operation an important place in ulcer therapy, though we indicated that this might eventually be mainly in support of other procedures (Orr and Johnson, 1947). Increasing experience has confirmed our view that vagus resection is a powerful weapon against ulcer recurrence, and, although it is primarily an attack on the fundamental diathesis and neurogenic hypersecretion, it will certainly bring about healing of many established ulcers.

Continued investigation has shown that vagotomy may be relied upon, when complete, to reduce spontaneous interdigestive gastric acid secretion substantially, and also to

*The largest group in the series here reported was operated upon at Hammersmith Hospital (Postgraduate Medical School of London? where this investigation was begun and has Iargely continued. diminish acid response to a meal or to histamine injection. Furthermore, these effects have been shown to endure in cases where repeated insulin tests have established the completeness of the nerve section.

Once an ulcer has penetrated deeply and caused gross scarring in the restricted area of the duodenum, healing of the surface breach alone cannot be relied upon to rid the patient of his symptoms, and removal of the distorted stenosed rigid segment of bowel may become necessary. Vagotomy alone will seldom suffice in such a case. At an earlier stage, however, when the ulcer is still confined ato the bowel wall, vagotomy by itself, with its negligible danger to life, may save the patient from years of semi-invalidism and pain with gradually mounting risks should he perforate or bleed.

\section{Choice of Patients}

The results achieved in a series of vagotomy cases will depend to a considerable degree upon the wisdom with which patients are selected for this operation. We have learned much from our failures, and are now able more confidently to say when vagotomy alone is likely to be a success and when it would be better combined with other procedures or not used at all. Selection must always be based upon very thorough investigation as well as upon certain special aspects of the history. Particularly important is the assessment of the relative prominence in the aetiology of hyperacid response to food, neurogenic hyperacidity, and excess of interdigestive and nocturnal secretion, and we employ special routine tests for this purpose.

The patient most suitable for vagotomy is one in whom there is a clear association between worry and relapse. This type of patient usually has a copious and very acid spontaneous night secretion and is often wakened at night. by pain. A not unusual finding in such a case is 500 to $1,000 \mathrm{ml}$. of night secretion containing 60 to 80 units of free $\mathrm{HCl}$. At the same time it may be remembered that vagotomy produces a lasting fall in acid response to food and to histamine injection.

One source of poor results with vagotomy alone is failure to recognize early pyloric stenosis. After vagus resection a quite moderate degree of narrowing may cause symptoms, as compensatory hyperactivity of gastric muscle has been abolished. We now realize the necessity for some form of by-pass operation whenever there is the least doubt of the absolute patency of the pylorus.

We have also learned that, whereas vagotomy will prevent recurrent duodenal ulcers and will usually completely heal an active ulcer confined to the bowel wall, once an ulcer has become grossly callous or has penetrated into the pancreas it may not heal after vagotomy alone, or, if it does heal, may cause recurrence of symptoms from contraction of scar tissue later. We now consider that such ulcers should be removed and that vagotomy should be added to prevent recurrence.

\section{Indications for Vagotomy}

An ulcer that shows a distinct tendency to recur under conditions of stress which cannot be eliminated or which are no more than the ordinary human lot should come to surgery, provided that the symptoms are not adequately controlled by simple medical measures while at work.

Vagotomy alone may be employed if at operation there is no hint of pyloric stenosis and the ulcer has not penetrated beyond the gut wall. The addition of gastro-enterostomy even in such cases is a wise precaution which may well become a routine measure with more experience. Only the fear that vagotomy might not ultimately prove an 